\title{
Postural Comparison of Dextrous and Ambidextrous Players and the Effects of Elastic Band Exercises on Postural Correction
}

\author{
Dr. T Vivekanadhan ${ }^{1}$, Bintu.T.Kalyan ${ }^{2}$ \\ ${ }^{1}$ Research Guide, Associate Professor, Department of B.P.E., Christ College Irinjalakuda. \\ ${ }^{2}$ Research scholar, Assistant professor, Department of Physical Education, Christ College Irinjalakuda.
}

\begin{abstract}
The purpose of the study was the postural comparison of dexterous and ambidextrous players and the effects of elastic band exercises on postural correction. Human posture is the basic thing that a sports man need for his sports performance at an optimum level. The postural development of a player is depends up on several factors like nature of physical activity, life style, heredity...This study aims to take postural comparison between the players who are using their one side of the body and the players are using their both side equally. In this study, the subjects were selected from various institutions in Kerala, India namely Kannur University Mangattuparamba Campus, Christ College Irinjalakuda, S N College Kannur, LNCP Trivandrum, Center for Physical Education Calicut University, ST. Thomas College Pala, ST. Thomas College Thrissur and St. Pius College Rajapuram. The investigator has visited these institutions and collected data directly from the subjects. A total of hundred $(N=100)$ subjects were selected for this study and the fifty $(n=50)$ from the each dextrose and ambidextrous groups. The New York Posture Rating Scale was utilized to measure the posture of subjects. Depending up on the deformity, the players were scored according to the specific norms of the test like 5 for good posture, 3 for average, 1 for poor posture. For the experimental purpose, a total of twenty $(N=20)$ deformed players were selected to this study and divided them in to two groups namely experimental group and control group. The experimental group was undergone for an experiment with the duration of 6 months by using exercise band. There was no experiment has taken by control group. At the end of the experimental period, there was a postural measurement has done by investigator for both experimental and control group. After taking the raw scores of the subjects, the percentage of postural deformity was calculated by using independent ' $t$ ' ratio. From the findings we would make understand that the ambi- dexterous players show comparatively good posture than the dexterous players. Posture of the cricket players was the most fatly than the other players. In the case of the anterior postural region cricket players and the lateral postural region the volley ball players had the poor postural level as compared to the other players. The swimmers had the good posture among the anterior and lateral region of posture. On regarding the findings of postural correction, the experimental group has shown a significant difference in the posture than the control group.
\end{abstract}

\section{Introduction}

In sports and games, different types of movements are there. In some games the players use their one side of the body predominantly. In the case of a right hand bowler in cricket, his right hand side is stronger than the left hand side because he needs to use his right side to perform the skill. The continuous use of the hand is leads to developing strong muscles on that particular area. These developments are causes to imbalance between muscles on the basis of its strength. In the case of a right arm fast bowler, his right deltoid muscles are stronger than the left side, and left oblique muscles are stronger than the right side. This improper toning of the muscles is slowly leads to the improper alignment of the spine. .E.g.: Badminton, cricket, javelin throw. In sports like weight lifting and swimming both hand come into play. So the both side of our body get equal strength. In the case of swimming, the swimmer uses his both hands equally for the execution of the skill. In this case his body gets equal strength on each side. This study aims to take postural comparison between the players who are using their one side of the body and the players are using their both side equally. In sports and games, different types of movements are there. In some games the players use their one side of the body predominantly. In the case of a right hand bowler in cricket, his right hand side is stronger than the left hand side because he needs to use his right side to perform the skill. The continuous use of the hand is leads to developing strong muscles on that particular area. These developments are causes to imbalance between muscles on the basis of its strength.

\section{Selection of subjects}

\section{Methodology}

In this study, the subjects were selected from various institutions in Kerala, India namely Kannur University Mangattuparamba Campus, Christ College Irinjalakuda, S N College Kannur, LNCP Trivandrum, Center for Physical Education Calicut University, ST. Thomas College Pala, ST. Thomas College Thrissur and 
St. Pius College Rajapuram. The investigator has visited these institutions and collected data directly from the subjects.

A total of hundred $(\mathrm{N}=100)$ subjects were selected for this study and the fifty $(\mathrm{n}=50)$ from the each dextrose and ambidextrous groups.

The New York Posture Rating Scale was utilized to measure the posture of subjects. For the experimental purpose, a total of twenty $(\mathrm{N}=20)$ deformed players were selected to this study and divided them in to two $(\mathrm{n}=10)$ groups namely experimental group and control group.

\section{Selection of variables}

Criterion variable - Body posture

Independent variables - Resistance band exercises

\section{Selection of test:}

New York postural test* was utilized for measuring the posture of selected players

\section{Experimental design}

In this study purposive random group design was utilized to determine the effect of resistance band exercise on postural corrective process.

\section{Administration of training program}

Total duration of the training program was 6 months with 2 days per week. The total duration of each training period was 60 minutes, including warm up, training and cooling down. There were two groups in this study named as band exercise group and control group. The control group hasn't take part in any training program.

Training exercises for experimental group

\begin{tabular}{|c|c|}
\hline No. & Resistance Band Exercises \\
\hline 1 & Single Arm Stretch Hold \\
\hline 2 & Double arm stretch back \\
\hline 3 & Seated Row \\
\hline 4 & Sitting - Upper Body Anterio-Medial \\
& Twist \\
\hline 5 & Sitting - Upper Body Posterio- Medial \\
Twist
\end{tabular}

Monthly intensity setting chart for six month plan

\begin{tabular}{|c|c|c|}
\hline Sl.No. & Month & Intensity \\
\hline 1 & October & Low \\
\hline 2 & November & Moderate \\
\hline 3 & December & Moderate \\
\hline 4 & January & High \\
\hline 5 & February & High \\
\hline 6 & March & High \\
\hline
\end{tabular}

- Load was depends on the personal improvement and ability

Weekly workout sessions chart

\begin{tabular}{|c|c|c|}
\hline \multirow{2}{*}{ Days } & \multicolumn{2}{|c|}{ Sessions } \\
\cline { 2 - 3 } & Exercise band group & Control group \\
\hline Sunday & No experiment & No experiment \\
\hline Monday & $*$ & No experiment \\
\hline Tuesday & No experiment & No experiment \\
\hline Wednesday & No experiment & No experiment \\
\hline Thursday & No experiment & No experiment \\
\hline Friday & $*$ & No experiment \\
\hline Saturday & No experiment & No experiment \\
\hline
\end{tabular}

$(*=$ work out sessions $)$ 


\section{Flow chart}

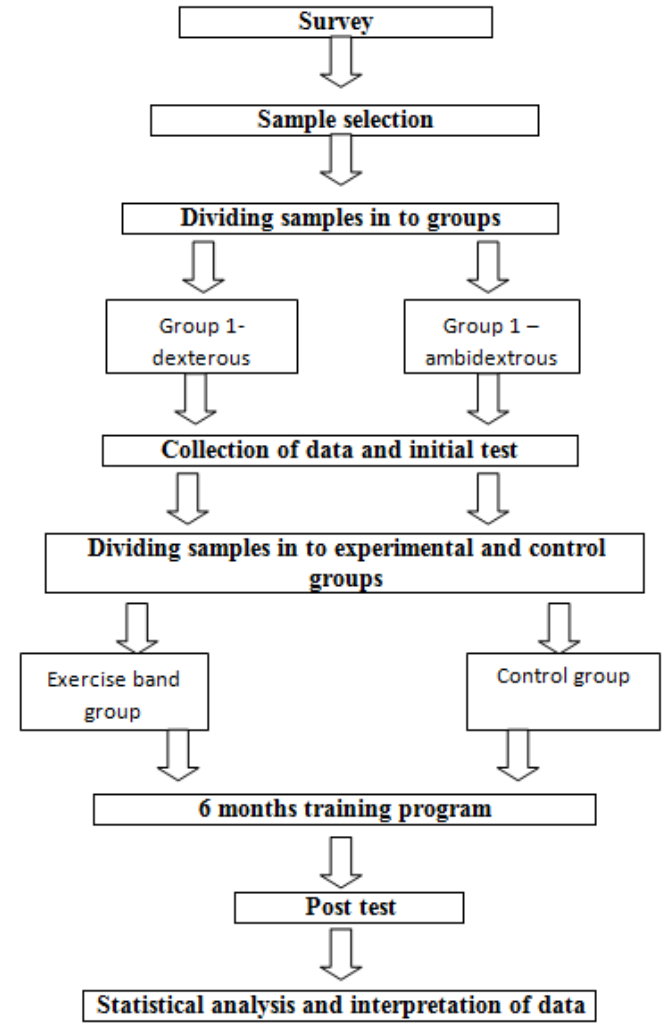

Statistical technique:

Independent' $t$ ' test was utilized for comparing the mean difference between dexterous and ambidextrous players on their posture and the difference of band exercise group and control group on posture.

\section{Results And Discussion}

Table No 1 Total score of anterior posture grade of selected players.

\begin{tabular}{|l|l|}
\hline BADMINTON & $\mathbf{2 4 0}$ \\
\hline CRICKET & $\mathbf{1 6 2}$ \\
\hline HAND BALL & $\mathbf{2 0 4}$ \\
\hline THROWERS IN ATHLETICS & $\mathbf{1 7 7}$ \\
\hline VOLLY BALL & $\mathbf{2 1 0}$ \\
\hline WEIGHT LIFTERS & $\mathbf{3 0 0}$ \\
\hline POWER LIFTERS & $\mathbf{3 0 0}$ \\
\hline BODY BUILDERS & $\mathbf{3 0 0}$ \\
\hline RUNNERS & $\mathbf{2 8 6}$ \\
\hline SWIMMERS & 300 \\
\hline
\end{tabular}

From the table 1, it is clear that the ambidextrous players (last five) scored more than the dexterous players (first five) in anterior region.

Table No 2 Total score of lateral posture grade of selected players.

\begin{tabular}{|l|l|}
\hline BADMINTON & 299 \\
\hline CRICKET & 322 \\
\hline HAND BALL & 328 \\
\hline THROWERS IN ATHLETICS & 332 \\
\hline VOLLY BALL & 327 \\
\hline WEIGHT LIFTERS & 336 \\
\hline POWER LIFTERS & 344 \\
\hline BODY BUILDERS & 340 \\
\hline RUNNERS & 346 \\
\hline SWIMMERS & 348 \\
\hline
\end{tabular}

From the table 2, it is clear that the ambidextrous players (last five) scored more than the dexterous players (first five) in lateral region. 
Table No 3 Total score of anterior and lateral posture grade of selected players.

\begin{tabular}{|l|l|}
\hline BADMINTON & 539 \\
\hline CRICKET & 484 \\
\hline HAND BALL & 532 \\
\hline THROWERS IN ATHLETICS & 509 \\
\hline VOLLY BALL & 537 \\
\hline WEIGHT LIFTERS & 636 \\
\hline POWER LIFTERS & 644 \\
\hline BODY BUILDERS & 640 \\
\hline RUNNERS & 632 \\
\hline SWIMMERS & 648 \\
\hline
\end{tabular}

From the table 3, it is clear that the ambidextrous players (last five) scored more than the dexterous players (first five) in both anterior and lateral region.

Table no: 4 Statistical Analysis of Data on the Posture $\mathrm{O}=$ of Dexterous and Ambidextrous Players

\begin{tabular}{|c|c|c|c|c|c|}
\hline GROUP & $\mathbf{N}$ & MEAN & STD.DEVIATION & $T$ & REQUIRED $\quad T$ \\
\hline DEXTROUS & 5 & 5.2020 & 23.50957 & & \\
\hline AMBIDEXTROUS & 5 & 6.4000 & 6.32456 & 11.003 & 2.015 \\
\hline
\end{tabular}

The obtained ' $t$ ' score was more than the required $t$ score, there for there were a significant difference in between dexterous and ambidextrous groups.

Table 5 Total score of anterior and lateral posture grade of experimental and control group

\begin{tabular}{|c|c|c|}
\hline & Experimental group & Control group \\
\hline Pre- test score & $\mathbf{4 8 6}$ & 490 \\
\hline Post test score & 528 & 482 \\
\hline
\end{tabular}

Table 6 Statistical Analysis of Data on Post Test Score

\begin{tabular}{|l|c|c|c|c|c|}
\hline GROUP & $\mathbf{N}$ & MEAN & STD.DEVIATION & T & REQUIRED \\
\hline Experimental & 10 & 50.31 & 6.57 & \multirow{2}{*}{ T } \\
\hline Control & 10 & 48.48 & 3.91 & 2 \\
\hline
\end{tabular}

\section{Findings}

1. There was a significant difference in between the scores of dexterous and ambidextrous players

2. The ambidextrous players had good body posture than the dexterous players

3. The experimental group has shown significant difference in the post test score than the pre test score there for the exercise band exercise is beneficial for postural correction

4. There weren't any significant chances in the pre and post test scores of control group.

\section{Recommendations}

Based on the findings of the study following recommendations has made;-

It can be conducted for

1. Different levels of players.

2. By opting different loading and equipment

3. Both sexes separately.

4. Athlete and non-athlete.

\section{References}

[1] Karahana Azize and N Bayraktarb, Determination of the Usage of Body Mechanics in Clinical Setting and Occurrence of Low Back Pain in Nurses, (2004)

[2] Kreichner, Glenn, Physical Education for Elementary School Children $8^{\text {th }}$ Edition, (1992)

[3] Kothiwala, D.B, Aplia for Making Physical Education a Subject for University Examination, Jounrnal of Physical Education and Sports, (1959).

[4] Letts M, Shapiro L, Mulder K, Klassen O, The Windblown Hip Syndrome in Total Body Cerebral Palsy . J Pediatr Orthop, (1984). 